\title{
Logical Structural Models with Multiplexors
}

J. Bokr, V. Jáně̌

The paper deals with the use of multiplexors in designing logical structural models.. The applications can be preferably used in designing morphology on EFGA chips and other programmable structures. Illustrative examples are included.

Keywords: Boolean function, Artjuchov-Shalyto extension, Shannon extension, Boolean function decomposition, multiplexor.

\section{Introduction}

The procedure in the design of logical structural models with multiplexors might seem to be complete. It appears, however, that the Artjuchov-Shalyto extension of the Boolean function, which models the performance of a multiplexor, leads to its mere "setting", and the generalised model of the multiplexor performance makes it possible to design structural models with multiplexors according to the disjoint decomposition of the given Boolean function.

\section{Boolean function}

Let the Boolean function $f:\{0,1\}^{m} \rightarrow\{0,1\}:\left\langle x_{1}, x_{2}, \ldots, x_{m}\right\rangle \mapsto y$

be given. If we denote the set $\left\{x_{i}\right\}_{i=1}^{m}$ of the function $f$ arguments by the symbol $X$, we can write $f(X)$ instead of $f\left(x_{1}, x_{2}, \ldots\right.$, $\left.x_{m}\right)$. Let us also write $f\left(x_{i}=\sigma_{i}\right)$ instead of $f\left(x_{1}, x_{2}, \ldots, x_{i-1}, \sigma_{i}\right.$, $\left.x_{i+1}, \ldots, x_{m}\right)$, where $\sigma_{i} \in\{0,1\}$. We require the function $f(X)$ to be minimal with respect to the number of arguments, i.e., not to contain fictive arguments; the argument $x_{i}$ is called fictive if $f\left(x_{i}=0\right)=f\left(x_{i}=1\right)$. The term Hamming weight $\boldsymbol{w}_{\boldsymbol{H}}$ of the function $f-w_{H} f-$ denotes the value of the arithmetic expression

$$
w_{H} f(X)=\sum_{\left\langle\sigma_{1}, \sigma_{2}, \ldots, \sigma_{m}\right\rangle \in\{0,1\}^{m}} f\left(\sigma_{1}, \sigma_{2}, \ldots, \sigma_{m}\right)
$$

Let $x^{\sigma}=x \sigma \vee \bar{x} \bar{\sigma}(\sigma \in\{0,1\})$; each Boolean function $f(X)$ can be expressed by means of a canonic normal disjunctive formula $-\operatorname{cndff} f(X)$

$$
f(X)=\underset{\left\langle\sigma_{1}, \sigma_{2}, \ldots, \sigma_{m}\right\rangle \in\{0,1\}^{m}}{\vee} x_{1}^{\sigma_{1}} x_{2}^{\sigma_{2}} \ldots x_{m}^{\sigma_{m}} \cdot f\left(\sigma_{1}, \sigma_{2}, \ldots, \sigma_{m}\right) .
$$

Then, if $w_{H} f<2^{m} / 2$ or $w_{H} f>2^{m} / 2$, or if $w_{H} f=2^{m} / 2$, it is preferable to write down the respective $\operatorname{cndf} f(X)$ or $c n d f$ $\bar{f}(X)$, or to apply the Artjuchov-Shalyto extension of the function $f(X)[1]$

$$
\begin{aligned}
& f(X)=x_{i} \oplus\left(\bar{x}_{i} f\left(x_{i}=0\right) \vee x_{i} \bar{f}\left(x_{i}=1\right)\right) \\
& f(X)=\bar{x}_{i} \oplus\left(\bar{x}_{i} \bar{f}\left(x_{i}=0\right) \vee x_{i} f\left(x_{i}=1\right)\right)
\end{aligned}
$$

the validity of which can be easily confirmed by supplying 0 or 1 for $x_{i}$.

Let a dichotomy $\left\{X_{1}, X_{0}\right\}$ be given on a set of $X$ arguments $x_{1}, x_{2},, x_{m}$ without loss of generality, such that $X_{1}=\left\{x_{1}, x_{2}, \ldots\right.$, $\left.x_{n}\right\}$ and $X_{0}=\left\{x_{n+1}, x_{n+2}, \ldots, x_{m}\right\}$, where $n<m$. Let the simple $k$-multiple $(k<n)$ disjoint decomposition of the function $f(X)$ be called the composition
$f(X)=\varphi\left(\varphi_{1}\left(X_{1}\right), \varphi_{2}\left(X_{1}\right), \ldots, \varphi_{k}\left(X_{1}\right), X_{0}\right)$.

The construction of the simple $k$-multiple $(k<n)$ disjoint decomposition of function $f(X)$ can be easily done by means of a decomposition by map[2, 3].

\section{Multiplexor}

The term multiplexor $(M X)[2,4,5]$ denotes a logical object modeled both in a parametrical and an algebraic way. See Fig. 1 , where $\mathrm{A}_{r}(r=1,2, \ldots, k)$ and $d_{j}\left(j=0,1, \ldots, 2^{k}-1\right)$ are the respective adjustable address-, and data-input ports:

$$
\begin{aligned}
y= & \operatorname{MX}\left(\varphi_{1}\left(X_{1}\right), \varphi_{2}\left(X_{1}\right), \ldots, \varphi_{k}\left(X_{1}\right)\right. \\
& \left.\mid g_{0}\left(X_{0}\right), g_{1}\left(X_{0}\right), \ldots, g_{2^{k}-1}\left(X_{0}\right)\right)= \\
& =\underset{j=0}{2^{k}-1} \varphi_{1}^{\sigma_{1}}\left(X_{1}\right) \varphi_{2}^{\sigma_{2}}\left(X_{1}\right) \ldots \varphi_{k}^{\sigma}\left(X_{1}\right) g_{j}\left(X_{0}\right)
\end{aligned}
$$
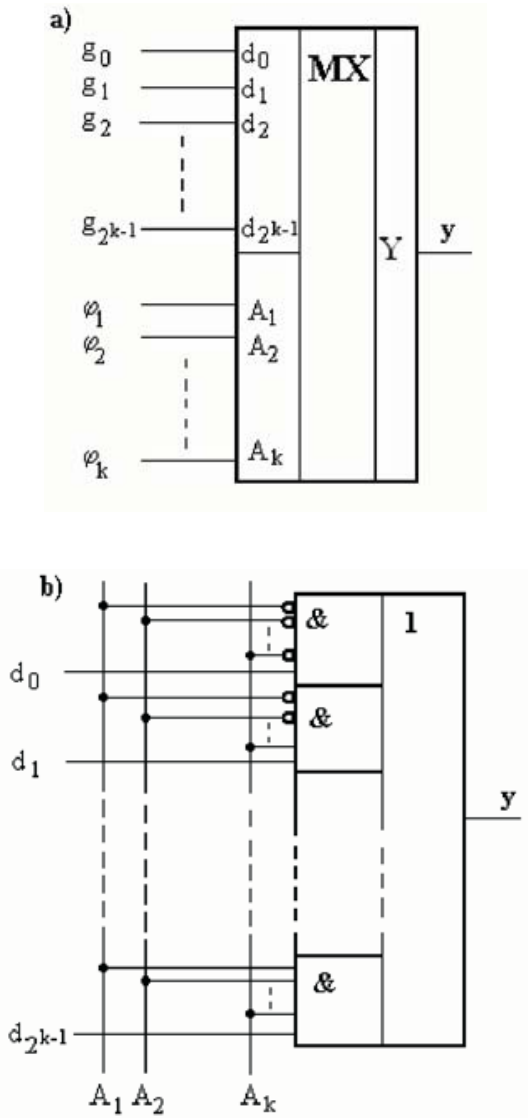

Fig. 1: a) Schematic diagram of a multiplexor, b) structural model of a multiplexor 
where

$$
j=\sigma_{1} \sigma_{2} \ldots \sigma_{k}=\sum_{r=1}^{k} \sigma_{r} 2^{k-r} .
$$

\section{Multiplexor and the Boolean function}

Let us provide the output port $M X$ with an element of anticoincidence such that $y=Y \oplus z$, where $z \in\left\{0,1, \bar{x}_{i}, x_{i}\right\}-$ see Fig. 2. Let us design a multiplexor modelled by the function $f(X)$ :

$$
\begin{aligned}
y & =z \oplus M X\left(x_{1}, x_{2}, \ldots, x_{m} \mid g_{0}, g_{1}, \ldots, g_{2^{m}-1}\right)= \\
& =\underset{\left\langle\sigma_{1}, \sigma_{2}, \ldots, \sigma_{m}\right\rangle \in\{0,1\}^{m}}{\vee} x_{1}^{\sigma_{1}} x_{2}^{\sigma_{2}} \ldots x_{m}^{\sigma_{m}} f\left(\sigma_{1}, \sigma_{2}, \ldots, \sigma_{m}\right) .
\end{aligned}
$$

Hence $g_{j}=f\left(\sigma_{1}, \sigma_{2}, \ldots, \sigma_{m}\right)$, where

$$
j=\sigma_{1}, \sigma_{2}, \ldots, \sigma_{m}=\sum_{i=1}^{m} \sigma_{i} 2^{m-i} .
$$

If it is more suitable to construct $y=\operatorname{cndf} f(X)$ or $y=\operatorname{cndf} \bar{f}(X),-$ see Par. $2-$, then the respective $z=0$ or $z=1$, for $y=f(X) \oplus 0$ or $y=f(X) \oplus 1$. If one cannot decide whether to construct $f(X)$ or $\bar{f}(X)$, then if

$\left.w_{H} f(X)\right|_{\sigma_{1}, \sigma_{2}, . ., \sigma_{m}\left\langle 2^{m} / 2\right.}<\left.w_{H} f(X)\right|_{\left.\sigma_{1}, \sigma_{2}, \ldots, \sigma_{m}\right\rangle 2^{m} / 2}$

or

$\left.w_{H} f(X)\right|_{\sigma_{1}, \sigma_{2}, \ldots, \sigma_{m}\left\langle 2^{m} / 2\right.}>\left.w_{H} f(X)\right|_{\left.\sigma_{1}, \sigma_{2}, \ldots, \sigma_{m}\right\rangle 2^{m} / 2}$

then $z=x_{1}$ and

or $z=\bar{x}_{1}$ and

$$
y=\bar{x}_{1} f\left(x_{1}=0\right) \vee x_{1} \bar{f}\left(x_{1}=1\right)
$$

respectively.

$$
\boldsymbol{y}=\bar{x}_{1} \bar{f}\left(x_{1}=0\right) \vee x_{1} f\left(x_{1}=1\right)
$$

Example 1: Construct a multiplexor realizing the function $f\left(x_{1}, x_{2}, x_{3}\right)=00010111$. Since $w_{H} f=4=2^{3} / 2$, as well as $\left.w_{H} f(X)\right|_{\sigma_{1}, \sigma_{2}, \ldots, \sigma_{m}\langle 4}=1<\left.w_{H} f(X)\right|_{\left.\sigma_{1}, \sigma_{2}, \ldots, \sigma_{m}\right\rangle 4}=3$, we obtain $z=x_{1}$ and since

$$
\begin{aligned}
f\left(x_{1}, x_{2}, x_{3}\right) & =\operatorname{MX}\left(x_{1}, x_{2}, x_{3} \mid 0,0,0,1,0,1,1,1\right)= \\
& =x_{1} \oplus \operatorname{MX}\left(x_{1}, x_{2}, x_{3} \mid d_{0}, d_{1}, d_{2}, d_{3}, d_{4}, d_{5}, d_{6}, d_{7}\right)
\end{aligned}
$$

we obtain

$d_{0}=d_{1}=d_{2}=d_{5}=d_{6}=d_{7}=0$ and $d_{3}=d_{4}=1$, i.e.

$y=M X\left(x_{1}, x_{2}, x_{3} \mid 0,0,0,1,1,0,0,0\right)$,

which is certainly a simpler setting of $M X$ than that of $d_{0}=d_{1}=d_{2}=d_{4}=0$ and $d_{3}=d_{5}=d_{6}=d_{7}=1$.

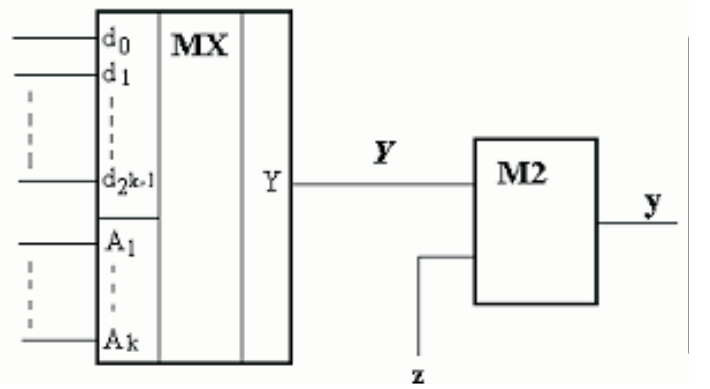

Fig. 2: Multiplexor and the element of the sum modulo 2 - M2

\section{Multiplexor and the simple k-multiple disjoint decomposition} where

Let $f\left(x_{1}, x_{2}, \ldots, x_{m}\right)=\varphi\left(\varphi_{1}\left(X_{1}\right), \varphi_{2}\left(X_{1}\right), \ldots, \varphi_{k}\left(X_{1}\right), X_{0}\right)$

$X_{1}=\left\{x_{1}, x_{2}, \ldots, x_{n}\right\}$ and $X_{0}=\left\{x_{n+1}, x_{n+2}, \ldots, x_{m}\right\}$,

be a simple k-multiple $(k<n)$ disjoint decomposition of the function $f\left(x_{1}, x_{2}, \ldots, x_{m}\right)$.

Let there be $\varphi_{r}=x_{r}(r=1,2, \ldots, k)$ with $k=n$ and let us construct the Shannon extension of the given function according to the arguments $x_{1}, x_{2}, \ldots, x_{n}$, without loss of generality

$$
\begin{aligned}
f\left(x_{1}, x_{2}, \ldots, x_{m}\right)= & \underset{\left\langle\sigma_{1}, \sigma_{2}, \ldots, \sigma_{n}\right\rangle}{\vee} x_{1}^{\sigma_{1}} x_{2}^{\sigma_{2}} \ldots x_{n}^{\sigma_{n}} . \\
& \cdot f\left(\sigma_{1}, \sigma_{2}, \ldots, \sigma_{n}, x_{n+1}, \ldots, x_{m}\right) .
\end{aligned}
$$

And further let

$$
\begin{aligned}
f\left(x_{1}, x_{2}, \ldots, x_{m}\right) & =\operatorname{MX}\left(x_{1}, x_{2}, \ldots, x_{n} \mid g_{0}, g_{1}, \ldots, g_{2^{n}-1}\right)= \\
& =2_{j=0}^{2^{n}-1} x_{1}^{\sigma_{1}} x_{2}^{\sigma_{2}} \ldots x_{n}^{\sigma_{n}} g_{j}
\end{aligned}
$$

hence $g_{j}=f\left(\sigma_{1}, \sigma_{2}, \ldots, \sigma_{n}, x_{n+1}, x_{n+2}, \ldots, x_{m}\right)$,

where $j=\sigma_{1} \sigma_{2} \ldots \sigma_{n}=\sum_{i=1}^{n} \sigma_{i} 2^{n-i}$.

Note that the selection of arguments according to which the Shannon extension of the given function $f\left(x_{1}, x_{2}, \ldots, x_{m}\right)$ is done depends completely on the view of the designer, and there is no reason to distinguish the development qualitatively according to the 'left-side' arguments $x_{1}, x_{2}, \ldots, x_{n}$ or 'right-side' arguments $x_{n+1}, x_{n+2}, \ldots, x_{m}$ of the function $f$, as stated in [1].

Example 2: Let the function $y=\vee(5,6,7,10,11,19,21,23$, $26,27,30,31)$ be given; design a structural model with $M X$ according to the Shannon development extension of the given function both according to arguments $x_{1}, x_{2}, x_{3}$ and according to arguments $x_{4}, x_{5}$, i.e., according to $y=\operatorname{MX}\left(x_{1}, x_{2}, x_{3} \mid h_{0}, h_{1}, \ldots, h_{7}\right)=M X\left(x_{4}, x_{5} \mid g_{0}, g_{1}, g_{2}, g_{3}\right)$. Thus, let us construct decomposition maps (Fig. 3.) hence
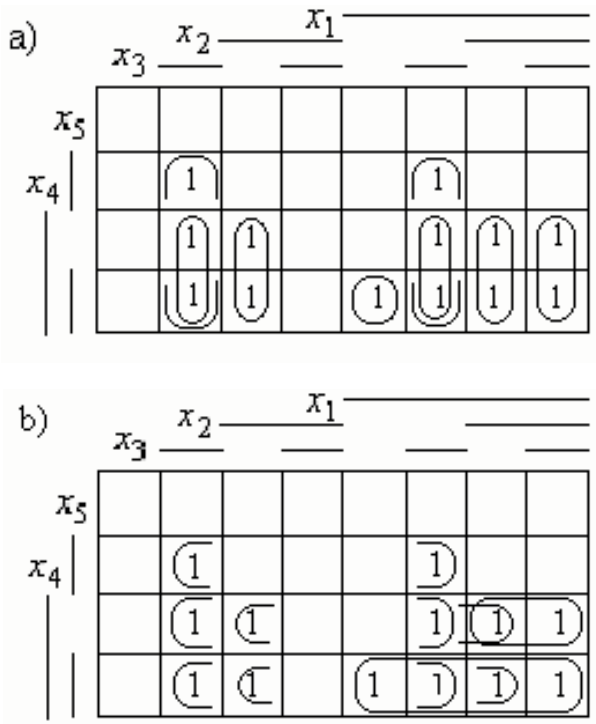

Fig. 3: Decomposition maps of the function from Example 2 
a)

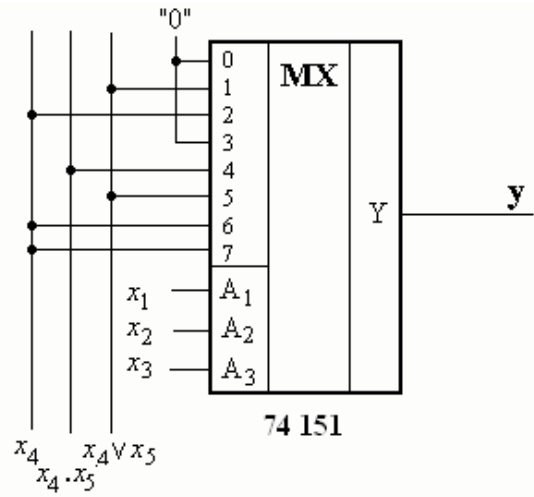

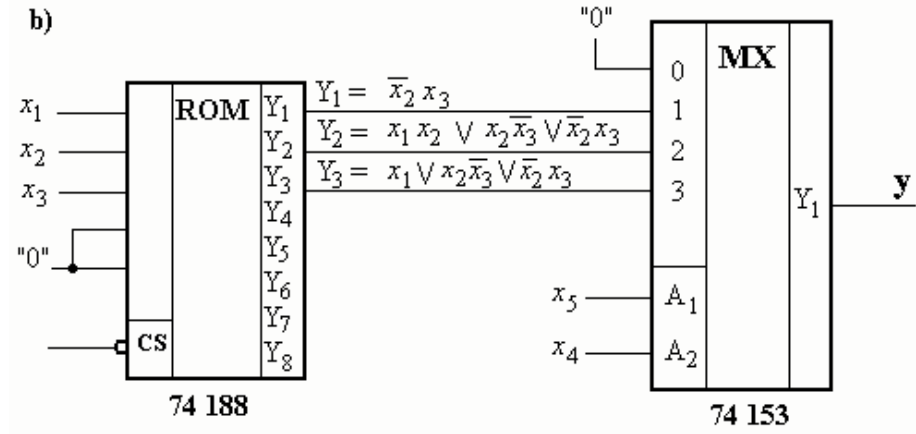

c)

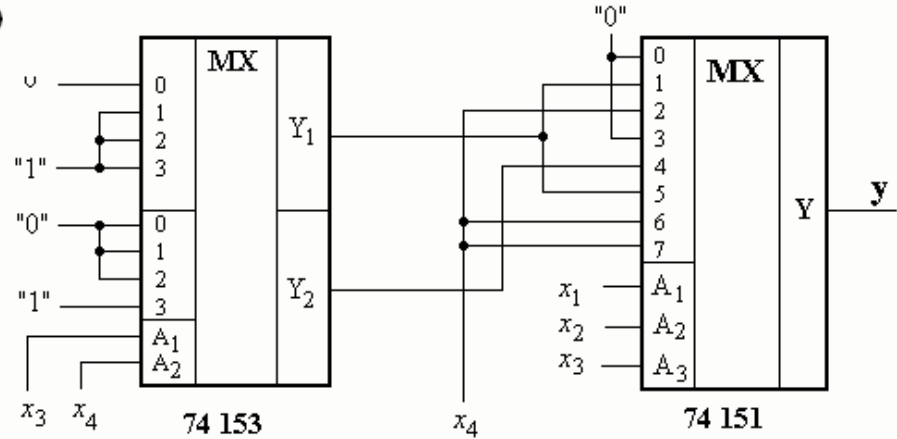

Fig. 4: Structural model with $M X$ from Example 2

$y=\bar{x}_{1} \bar{x}_{2} \bar{x}_{3}(0) \vee \bar{x}_{1} \bar{x}_{2} x_{3}\left(x_{4} \vee x_{5}\right) \vee \bar{x}_{1} x_{2} \bar{x}_{3}\left(x_{4}\right) \vee$

$\vee \bar{x}_{1} x_{2} x_{3}(0) \vee x_{1} \bar{x}_{2} \bar{x}_{3}\left(x_{4} x_{5}\right) \vee x_{1} \bar{x}_{2} x_{3}\left(x_{4} \vee x_{5}\right) \vee$

$\vee x_{1} x_{2} \bar{x}_{3}\left(x_{4}\right) \vee x_{1} x_{2} x_{3}\left(x_{4}\right)$

as well as

$\boldsymbol{y}=\bar{x}_{4} \bar{x}_{5}(0) \vee \bar{x}_{4} x_{5}\left(\bar{x}_{2} x_{3}\right) \vee x_{4} \bar{x}_{5} \cdot\left(x_{1} x_{2} \vee x_{2} \bar{x}_{3} \vee \bar{x}_{2} x_{3}\right) \vee$

$\vee x_{4} x_{5}\left(x_{1} \vee x_{2} \bar{x}_{3} \vee \bar{x}_{2} x_{3}\right)$.

Hence the structural models from Fig. 4 . Note that in Fig. 4b) a ROM module is suggested and in Fig. 4c) the structure is realized only with multiplexer modules.

Let a simple k-multiple disjoint decomposition

$f\left(x_{1}, x_{2}, \ldots, x_{m}\right)=\varphi\left(\varphi_{1}\left(X_{1}\right), \varphi_{2}\left(X_{1}\right), \ldots, \varphi_{k}\left(X_{1}\right), X_{0}\right)$

be given, where $\varphi$ will be termed an outer function and the functions $\varphi 1(i=1,2, \ldots, k)$ will be denoted inner functions. And, further, let

$f\left(x_{1}, x_{2}, \ldots, x_{m}\right)=$

$=\operatorname{MX}\left(\varphi_{1}\left(X_{1}\right), \varphi_{2}\left(X_{1}\right), \ldots, \varphi_{k}\left(X_{1}\right) \mid g_{0}, g_{1}, \ldots, g_{2^{k}-1}\right)$

Hence

where

$$
g_{j}=\left(\varphi_{1}\left(X_{1}\right), \varphi_{2}\left(X_{1}\right), \ldots, \varphi_{k}\left(X_{1}\right), X_{0}\right)
$$

$j=\sigma_{1}, \sigma_{2}, \ldots, \sigma_{n}=\sum_{i=1}^{n} \sigma_{i} 2^{n-i}$.

Example 3: Construct a structural model with $M X$ according to the decomposition $y=\varphi\left(\varphi_{1}\left(x_{1}, x_{2}, x_{3}\right), \varphi_{2}\left(x_{1}, x_{2}, x_{3}\right), x_{4}, x_{5}\right)$

of the function $y$ from Example 2. According to the decomposition map (Fig. 5) we obtain

$$
\begin{aligned}
& \varphi_{1}\left(x_{1}, x_{2}, x_{3}\right)=x_{1} \bar{x}_{2} \vee \bar{x}_{2} x_{3} \\
& \varphi_{2}\left(x_{1}, x_{2}, x_{3}\right)=\bar{x}_{1} x_{2} x_{3} \vee \bar{x}_{2} \bar{x}_{3}
\end{aligned}
$$

for the inner functions.

Since

$$
\boldsymbol{y}=\operatorname{MX}\left(\varphi_{1}, \varphi_{2} \mid g_{0}, g_{1}, g_{2}, g_{3}\right)
$$

we obtain

$y=\bar{\varphi}_{1} \bar{\varphi}_{2}\left(x_{4}\right) \vee \bar{\varphi}_{1} \varphi_{2}(0) \vee \varphi_{1} \bar{\varphi}_{2}\left(x_{4} \vee x_{5}\right) \vee \varphi_{1} \varphi_{2}\left(x_{4} x_{5}\right)$ and hence the structural model in Fig. 6.

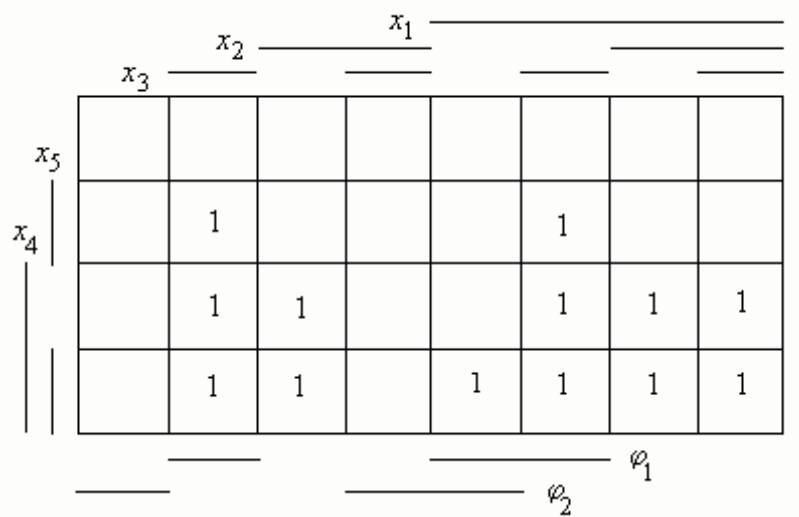

Fig. 5: Decomposition map of the function from Example 3 




Fig. 6: Structural model with MX prescribed by the decomposition from Example 3

\section{Conclusions}

The multiplexer appears to be a very helpful MSI module. The design of structural models is sufficiently simple and suitable also for the implementation of logical functions on chips provided with FPGA or FPD.

\section{References}

[1] Šalyto, A. A.: Metody apparatnoj i programmnoj realizacii algoritmov. Nauka, Sankt-Peterburg 2000.

[2] Bokr, J., Jáneš,V.: Logické systémy. Vydavatelství ČVUT, Praha 1999.

[3] Bokr.J.: "Sovmestnaja dekompozicija sistem bulevych funkcij." Avtomatika i vyčislitelnaja technika, 2000, No. 2, p. 38-44.

[4] Frištacký, N. at al..: Logické systémy. Bratislava/Praha, ALFA/SNTL 1986.

[5] Liebig, H., Thome, S.: Logischer Entwurf digitaler Systeme. Springer, Berlin - Tokio 1996.
Doc. Ing. Josef Bokr, CSc.

e-mail:bokr@kiv.zcu.cz

Department of Information and Computer Science

University of West Bohemia

Faculty of Applied Sciences

Universitní 22

30614 Pilsen, Czech Republic

Doc. Ing. Vlastimil Jáně̌, CSc.

e-mail:janes@fd.cvut.cz

Department of Control and Telematics

Czech Technical University in Prague

Faculty of Transportation Sciences

Konviktská 20

11000 Prague 1, Czech Republic 